\section{Response to: 'Role of ANA testing in the classification of patients with systemic lupus erythematosus' by Pisetsky et al}

In their letter, ${ }^{1}$ Drs Pisetsky, Spencer, Rovin and Lipsky very appropriately continue a highly relevant discussion on antinuclear antibody (ANA) testing. As Pisetsky et al point out, we had originally intended to specify ANA positivity on Hep-2 immunofluorescent testing, but grappled with the reality that increasingly other types of ANA testing are employed. Thus, the European League Against Rheumatism (EULAR)/American College of Rheumatology (ACR) SLE classification criteria steering committee discussed the issues made transparent by Dr Pisetsky et $a l^{2}$ and we think that we have come to a solution that is feasible: the EULAR/ACR criteria allow for other positive ANA tests in addition to HEp-2 immunofluorescence. ${ }^{34} \mathrm{We}$ agree that more research needs to be performed, both to understand the natural history of ANA positivity over time in SLE and to compare the performance characteristics of different assays.

ANA are still a useful concept, particularly for guiding physicians who are not experts on connective tissue diseases, and the strength of ANA lies in the sensitivity, not specificity of the test, in sharp contrast to anti-Sm antibodies, for example. ${ }^{5}$ Accordingly, the position as entry criterion appears appropriate, and reflective of their routine role as a screening test. ${ }^{3-5}$ Allowing for other tests and taking historical ANA into account improves sensitivity.

While we have had very low percentages of persistently ANA negative patients in our cohorts, ${ }^{346}$ classifying this rather small subset of patients remains a research issue. ${ }^{34}$ To include the subset of ANA negative patients into trials or studies may dilute findings. There is no doubt that such patients exist, and this has been openly discussed in our criteria manuscript. ${ }^{34}$ Importantly, however, we maintain that classification criteria are not diagnostic criteria-diagnosis remains within the judgement of appropriately trained healthcare professionals.

Rather than submitting to suboptimal test results, we also think that it is time to stand up for high quality testing with an appropriate feedback system based on the clinical accuracy of individual test results. Cheap, suboptimal tests may have costly and potentially even dangerous consequences, leading to unnecessary investigations as well as to delayed therapy. These issues may outweigh the higher convenience for laboratories and the resulting lower testing cost, but have not been greatly appreciated.

We fully agree with Dr Pisetsky and colleagues that more research on test systems is essential, and hope that our criteria will give this debate more visibility. We also think that immunological testing without rheumatologists providing direct feedback on ill-fitting results deprives the healthcare system of a highly valuable safety catch. Rheumatologists worldwide need to be very clear that the accuracy of immunological tests is essential, for diagnosis as well as for classification.

\footnotetext{
Martin Aringer $\odot,{ }^{1}$ Karen H Costenbader, ${ }^{2}$ Thomas Dörner $\odot{ }^{3}$ Sindhu R Johnson ${ }^{4}$
}

${ }^{1}$ Division of Rheumatology, Department of Medicine III, University Medical Center and Faculty of Medicine, TU Dresden, Dresden, Germany

${ }^{2}$ Division of Rheumatology, Immunology and Allergy, Department of Medicine, Brigham and Women's Hospital, Harvard Medical School, Boston, Massachusetts, USA

${ }^{3}$ Department of Rheumatology and Clinical Immunology, Charité -

Universitätsmedizin Berlin, Corporate member of Freie Universität Berlin, HumboldtUniversität zu Berlin, and Berlin Institute of Health, Berlin, Germany

${ }^{4}$ Division of Rheumatology, Department of Medicine, Toronto Western Hospital, Mount Sinai Hospital; Institute of Health Policy, Management and Evaluation, University of Toronto, Toronto, Ontario, Canada

Correspondence to Professor Martin Aringer, Internal Medicine III, Medical Faculty, Technical University of Dresden, Dresden D-01307, Germany;

martin.aringer@uniklinikum-dresden.de

Handling editor Josef S Smolen

Contributors All four authors have drafted the response together and approved of the final version.

Funding The authors have not declared a specific grant for this research from any funding agency in the public, commercial or not-for-profit sectors.

Competing interests None declared.

Patient consent for publication Not required.

Provenance and peer review Commissioned; internally peer reviewed.

(c) Author(s) (or their employer(s)) 2021. No commercial re-use. See rights and permissions. Published by BMJ.

\section{Check for updates}

To cite Aringer M, Costenbader KH, Dörner T, et al. Ann Rheum Dis 2021;80:e125.

Received 18 September 2019

Revised 28 September 2019

Accepted 30 September 2019

Published Online First 11 October 2019

\section{Linked}

- http://dx.doi.org/10.1136/annrheumdis-2019-216259

Ann Rheum Dis 2021;80:e125. doi:10.1136/annrheumdis-2019-216337

\section{ORCID iDs}

Martin Aringer http://orcid.org/0000-0003-4471-8375

Thomas Dörner http://orcid.org/0000-0002-6478-7725

\section{REFERENCES}

1 Pisetsky DS, Spencer DM, Rovin B, et al. Role of ANA testing in the classification of patients with systemic lupus erythematosus. Ann Rheum Dis 2021;80:e124.

2 Pisetsky DS, Spencer DM, Lipsky PE, et al. Assay variation in the detection of antinuclear antibodies in the sera of patients with established SLE. Ann Rheum Dis 2018;77:911-3

3 Aringer M, Costenbader K, Daikh D, et al. 2019 European League against Rheumatism/ American College of rheumatology classification criteria for systemic lupus erythematosus. Ann Rheum Dis 2019;78:1151-9.

4 Aringer M, Costenbader K, Daikh D, et al. 2019 European League against Rheumatism/ American College of rheumatology classification criteria for systemic lupus erythematosus. Arthritis Rheumatol 2019;71:1400-12.

5 Aringer M, Dörner T, Leuchten N, et al. Toward new criteria for systemic lupus erythematosus-a standpoint. Lupus 2016;25:805-11.

6 Mosca M, Costenbader KH, Johnson SR, et al. Brief report: how do patients with newly diagnosed systemic lupus erythematosus present? A multicenter cohort of early systemic lupus erythematosus to inform the development of new classification criteria. Arthritis Rheumatol 2019;71:91-8. 